\title{
PERANCANGAN WEBSITE RUMAH BACA AL-SYAJARAH SEBAGAI MEDIA PROMOSI
}

\author{
Mega Orina Fitri \\ Prodi D3 Ilmu Perpustakaan UIN Imam Bonjol Padang \\ E-mail: orina_95@yahoo.com
}

\begin{abstract}
Abstrak: Penelitian ini dilatarbelakangi oleh masih rendahnya jumlah pengunjung rumah baca Al-syajarah akibat ketidaktahuan masyarakat, disertai dengan mahalnya biaya promosi di media cetak dan televisi, dan pesatnya perkembangan teknologi dan informasi yang dapat menjangkau tempat yang luas. Karena itu pada dibuat website untuk rumah baca Alsyajarah di Padang, sebagai media promosi agar dapat menarik minat masyarakat untuk berkunjung ke rumah baca tersebut. Penelitian ini berupa penelitian pengembangan, dengan menggunakan metode penelitian kualitatif. Adapaun prosedur penelitian meliputi analisis kebutuhan, perancangan model, pengembangan produk, dan uji coba lapangan. Hasil akhir penelitian ini berupa website rumah baca Al-syajarah yang ternyata dapat meningkatkan eksistensi dan mempopulerkan rumah baca tersebut ke masyarakat di kota Padang. Hal ini dibuktikan dengan semakin bertambahnya jumlah pengunjung dari waktu ke waktu.
\end{abstract}

Kata kunci: Media promosi, Rumah baca Al-syajarah, Website.

\section{PENDAHULUAN}

alah satu jenis perpustakaan adalah Taman Bacaan Masyarakat (TBM) atau dikenal juga sebagai rumah baca. Rumah baca adalah hasil swadaya orang pribadi ataupun masyarakat. Secara definisi, rumah baca dapat diartikan sebagai tempat berkumpul untuk membaca. Rumah baca bertujuan didirikan untuk menyediakan dan mengupayakan ketersediaaan akses informasi yang mendukung proses belajar mengajar, penelitian, dan pengabdian masyarakat. (Eriska dan Ramansyah,2017).

Salah satu rumah baca yang ada di Padang dengan koleksi yang cukup banyak adalah Rumah Baca Al-syajarah. Rumah baca yang berlokasi di Lubuk Lintah Padang dan didirikan oleh Dr,Raichul Amar, salah seorang pensiunan dosen PNS dari Universitas Islam Negeri (UIN) Imam Bonjol Padang ini memiliki 7224 eksemplar koleksi, yang bersumber dari hasil beli, hasil karya pemiliknya, dan sumbangan intistusi/pribadi. Jenis koleksi berupa buku referensi, karya umum, hokum, kependudukan, agama, tanah, hutan, hewan, tumbuhan, biologi, pencemaran lingkungan dll.. Koleksi terbanyak adalah mengenai Lingkungan Hidup. Selain itu juga terdapat sekitar 11.000 koleksi foto dokumentasi .

Tetapi, banyaknya jumlah koleksi rumah baca ini berbanding terbalik dengan jumlah pengunjungnya. Berdasarkan hasil observasi dan wawancara, rata-rata per bulan hanya sekitar 10-20 orang yang datang berkunjung. Bahkan pernah dalam sebulan sama 
sekali tidak ada pengunjung yang dating padahal rumah baca ini terbuka untuk umum, dan dapat dipinjam koleksinya secara gratis. Hal ini disebabkan lokasi rumah baca yang cukup tersembunyi dan kurangnya promosi.

Untuk promosi seperti media cetak dan televisi, diperlukan biaya yang cukup besar. Padahal rumah baca yang didirkan untuk meningkatkan minat baca masyarakat terutama dalam masalah lingkungan hidup ini bersifat sosial atau nirlaba. Hal ini tentu memberatkan pemiliknya yang seorang pensiunan PNS.

Seperi diketahui saat ini perkembangan dan pengunaan teknologi informasi sangatlah pesat, terutama di bidang internet. Menurut Nielsen (2015) seperti yang dikutip oleh Sukarno (2016), untuk tahun 2014 saja sudah terdapat 71 juta orang pengguna internet di Indonesia. Dari jumlah tersebut, 41 juta pengguna mengakses internet melalui smartphone, dan 70 juta pengguna mengakses media sosial.

Salah satu bentuk dari perkembangan teknologi informasi adalah adanya website yang dapat digunakan sebagai media promosi yang murah meriah bahkan gratis. Karena itu penelitian ini bertujuan untuk menganalisis dan merancang suatu website untuk Rumah Baca Al-syajarah Padang, sehingga dapat menjadi media promosi yang efektif guna meningkatkan jumlah pengunjung, dan pada akhirnya dapat meningkatkan minat baca, terutama pada masyarakat sekitarnya.

\section{METODE PENELITIAN}

\section{A. Jenis dan Lokasi Penelitian}

Dalam penelitian ini penulis menggunakan jenis penelitian kualitatif yang bersifat pengembangan produk yang digunakan dalam bidang pendidikan. Sedangkan lokasi penelitian adalah di Padang.

\section{B. Teknik dan Instrumen Pengumpulan Data}

Dalam melakukan penelitian ini, digunakan teknik/metode observasi, wawancara dan dokumentasi dalam mengumpulkan data. Instrumen yang digunakan panduan observasi, pedoman wawancara dan daftar pertanyaan, serta daftar checklist dan tabel.

\section{Jenis Data}

\section{Data Primer}

Data primer diperoleh langsung dari hasil observasi di rumah baca Al-syajarah, Lubuk Lintah Padang. Selain itu data primer juga diperoleh dari hasil wawancara terhadap pemilik dan pemustaka rumah baca tersebut .

\section{Data Sekunder}

Data sekunder pada penelitian ini berasal dari berbagai referensi seperti jurnal dan sumber bacaan lain yang berhubungan dengan masalah yang dibahas. Data sekunder digunakan sebagai tambahan pengetahuan dan menjadi referensi dalam penelitian.

\section{KONSEP DAN PERANCANGAN}

\section{A. Media Promosi dengan Menggunakan Website}

Seperti diketahui walaupun koleksi suatu rumah baca / perpustakaan sangat bagus dan lengkap, dan sistem yang digunakan sangat canggih, tetapi jika hanya sedikit yang 
berkunjung ke perpustakaan, maka rumah baca / perpustakaan tersebut tidak akan berjalan. Karena itu diperlukan promosi.

Dengan melakukan promosi, terjadi proses pendekatan informasi kepada pemustaka. Pemustaka menjadi tahu berbagai fasilitas dan layanan apa saja yang tersedia. Sedangkan yang belum tahu atau yang sudah tahu tapi belum pernah memanfaatkan jasa layanan, akan mengenal dan kemudian tertarik untuk datang.

Seiring dengan perkembangan teknologi, promosi perpustakaan, dalam hal ini rumah baca, dapat menggunakan berbagai media, baik media konvensional, maupun media internet. Media konvensional seperti media cetak (flyer, brosur, Koran, dll). Sedangkan media internet misalkan dengan membuat website.

Salah satu kelemahan menggunakan media konvensional adalah dari sisi biaya yang cukup mahal. Untuk mencetak brosur misalnya, diperlukan biaya yang tidak sedikit. Sedangkan jika digunakan website, biaya dapat ditekan bahkan bisa jadi gratis jika dapat mendesain sendiri website dan juga digunakan alamat hosting yang tidak berbayar.

Karena itu, penelitian kali ini mengangkat topik perancangan website rumah baca Al-syajarah. Website rumah baca akan dibuat menarik dengan berisi beragam informasi mengenai koleksi, kegiatan, dan rumah baca itu sendiri. Dengan demikian diharapkan dapat menarik minat masyarakat untuk berkunjung, sehingga angka pengunjung rumah baca tersebut semakin meningkat.

\section{B. Joomla}

Pembuatan website pada umumnya terbagi menjadai dua yaitu Framework dan CMS (Content Management System). Framework merupakan kerangka kerja aplikasi atau software dengan menggunakan coding (pengkodean). Sedangkan CMS adalah suatu aplikasi berbasis web yang digunakan untuk mengatur konten website, dengan menyediakankan template. Salah satu contoh CMS adalah Joomla.

Joomla adalah CMS yang berisfat open source berbasis PHP dan MySQ unuk mengelola isi (content) sebuah website. Joomla merupakan salah satu CMS terpopuler di dunia, umumnya disediakan gratis oleh hosting provider. Joomla terdiri dari tiga element : web server yaitu Apache, script yang digunakan adalah PHP, dan DBMS-nya adalah My SQL.

\section{Perancangan Website}

Website ini diberi nama selaras dengan nama rumah baca Al-syajarah agar mempermudah pengguna dalam menemukan dan menelusurinya. Website dikembangkan menggunakan CMS (Content Management System) dengan tool Joomla. Pemilihan tool ini karena Joomla memiliki fitur editor dan optimisasi mesin pencari (SEO) yang dapat meningkatkan rating web, serta terdapat opsi yang lebih mudah dioperasikan. Joomla cocok untuk pengguna website yang lebih berpengalaman karena Joomla lebih fleksibel baik untuk back end maupun front end-nya (Riyanto, 2002).

Untuk membuat suatu website, terlebih dahulu diperlukan rancangan bentuk dan isi (content) dari halaman website tersebut. Adapun bentuk rancangan/model secara umum dari halaman website Rumah Baca Al-syajarah dapat dilihat pada Gambar 1 berikut ini. 


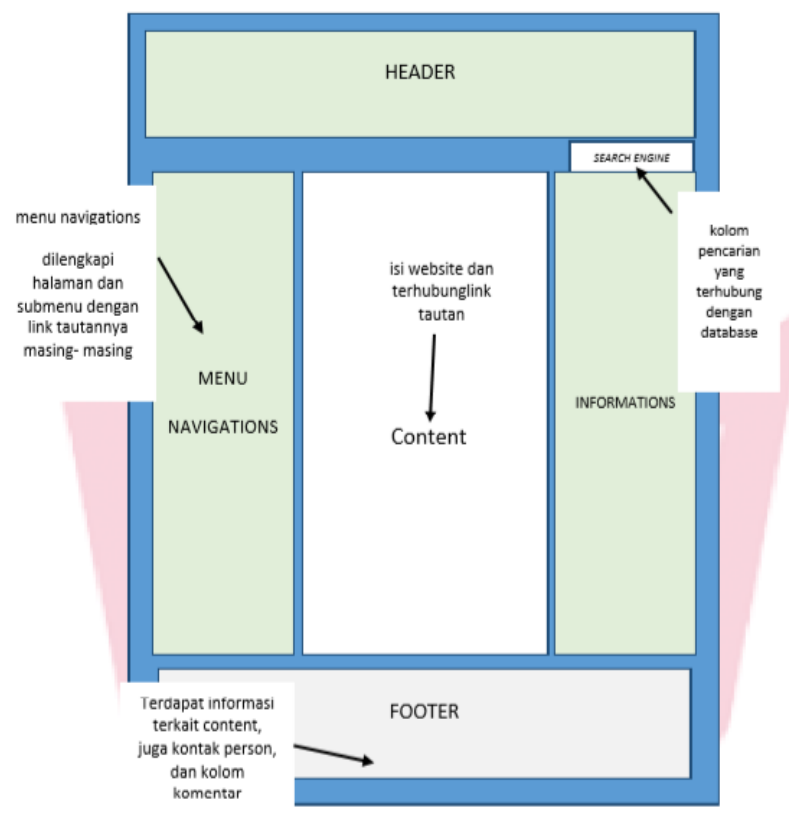

Gambar 1. Rancangan halaman website Rumah Baca Al-syajarah.

\section{HASIL DAN PEMBAHASAN}

Setelah diaplikasikan hasil rancangan/model tersebut dengan menggunakan Joomla, maka diperoleh tampilan website rumah baca Al-Syajarah. Beberapa dari tampilan tersebut adalah seperti dilihat pada gambar-gambar berikut ini.

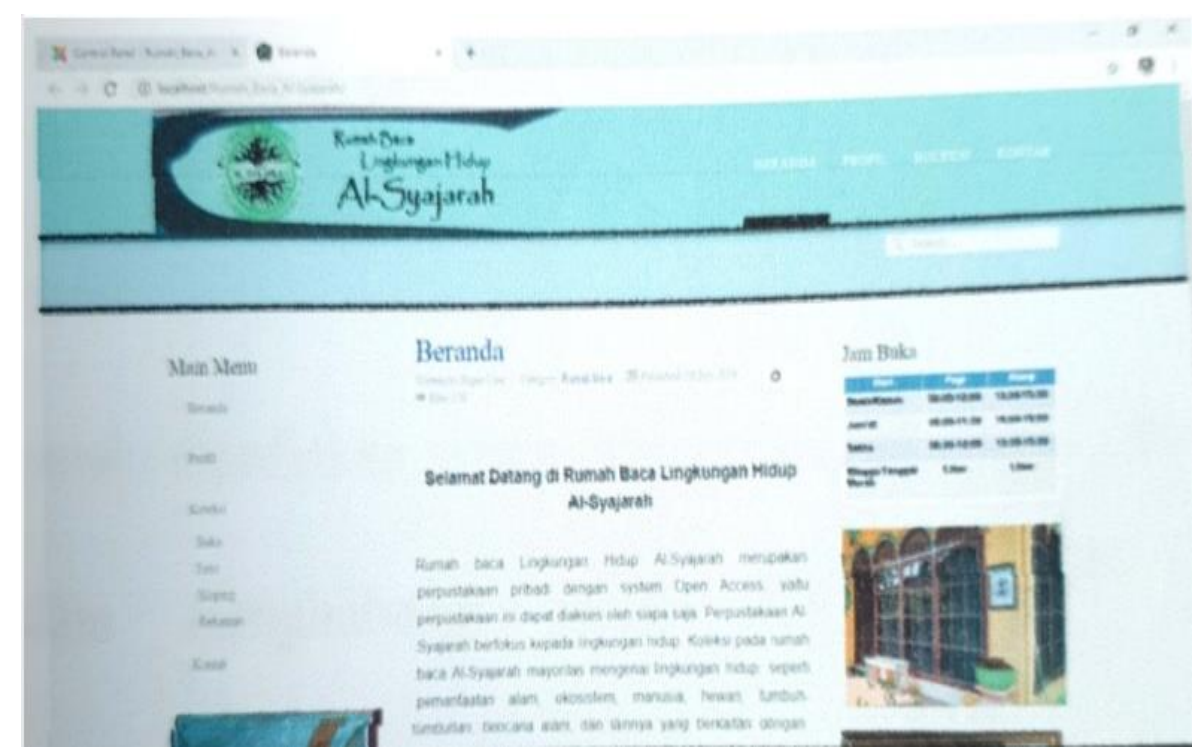

Gambar 2. Halaman Beranda dari website Rumah Baca Al-syajarah.

Gambar 2 memperlihatkan tampilan pada halaman awal website. Halaman awal website terbagi beberapa bagian yaitu: 
1. Main Menu yang berisi menu navigasi website secara keseluruhan.

2. Beranda yang berisi penjelasan mengenai rumah baca Al-syajarah.

3. Berbagai informasi lain yang terkait dengan rumah baca tersebut seperti Jam Buka, foto tampak depan rumah baca, dll.

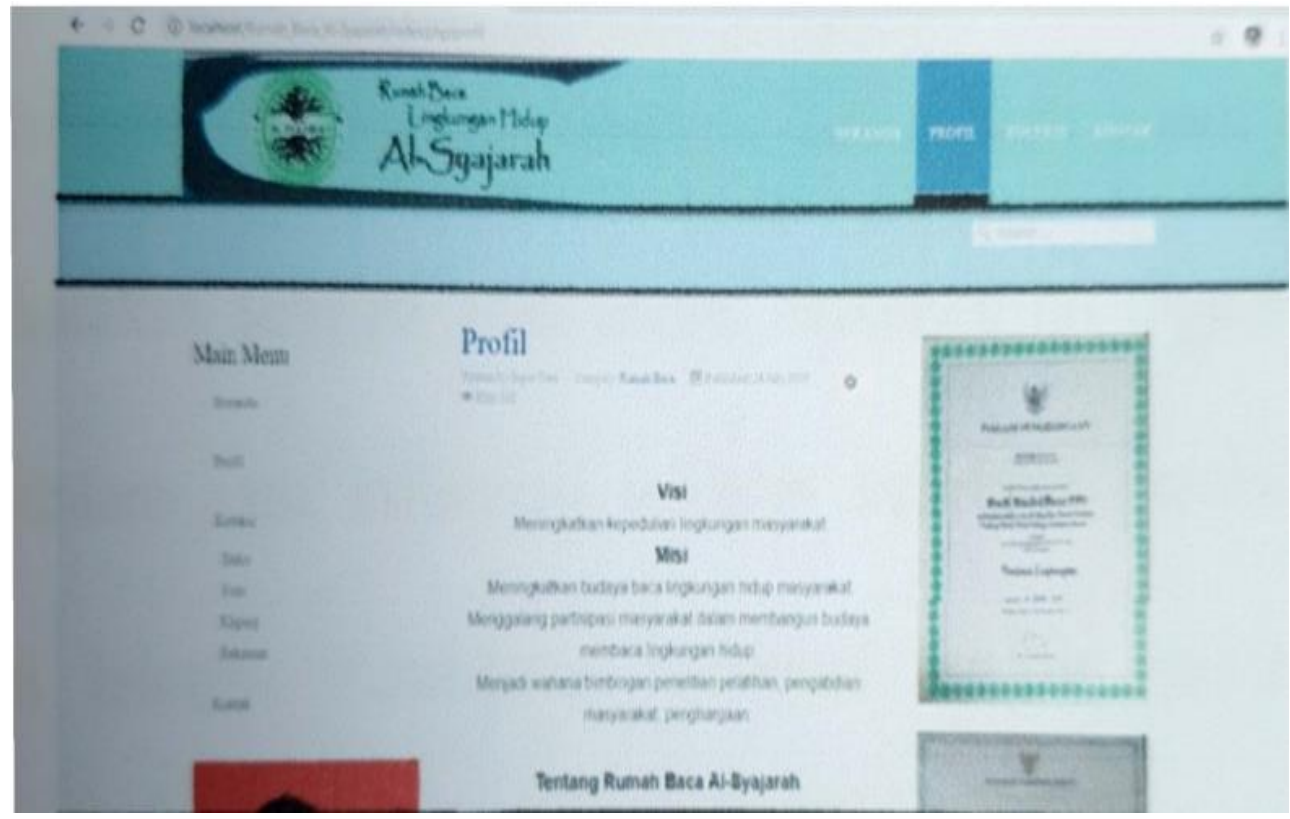

Gambar 3. Halaman Profil Rumah Baca Al-syajarah.

Gambar 3 adalah tampilan untuk halaman Profil Rumah Baca, yang berisi visi misi latar belakang pendirian rumah baca tersebut. Di bagian kiri Profil terdapat Main Menu. Sedangkan di bagian kanannya terdapat berbagai macam foto penghargaan yang pernah diraih serta foto pemilik sekaligus pendiri rumah baca tersebut.

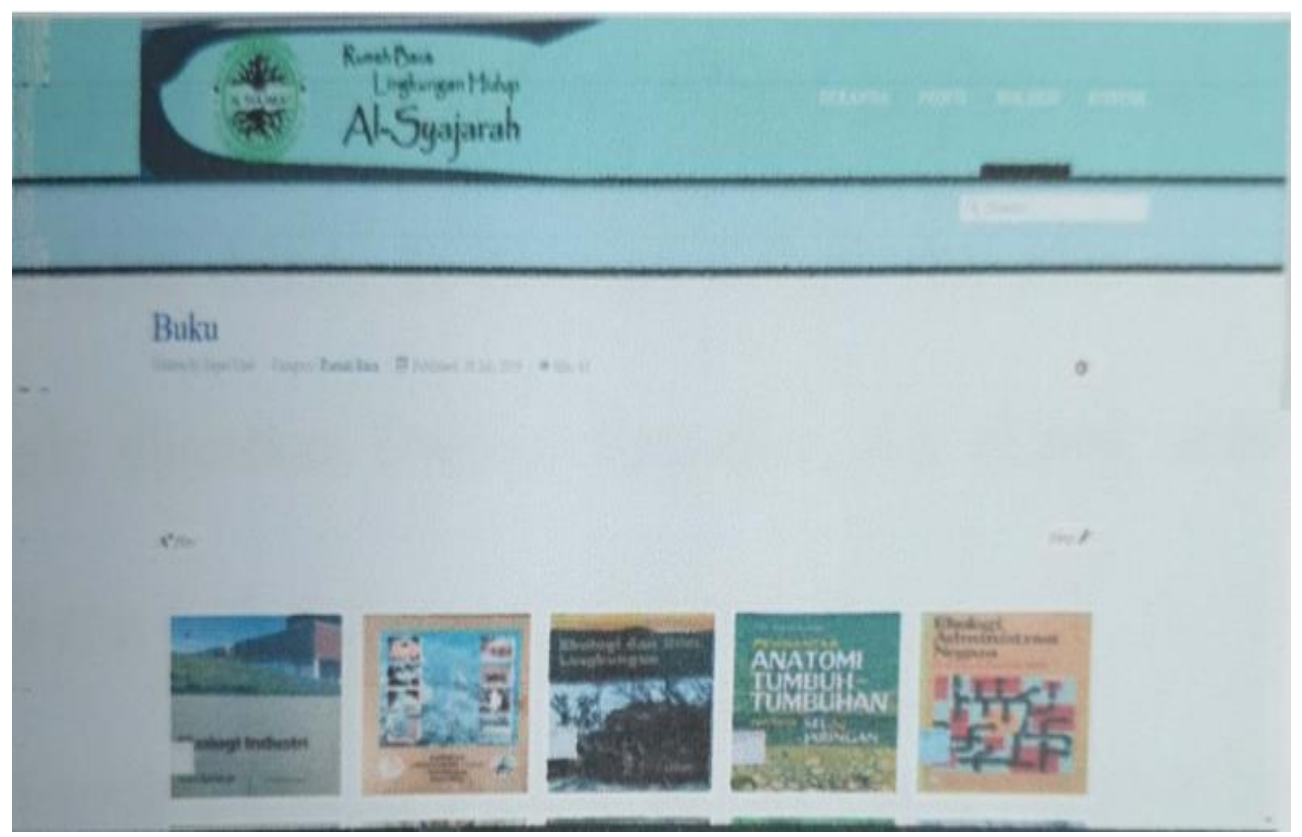

Gambar 4. Halaman Koleksi Rumah Baca Al-syajarah. 
Gambar 4 memperlihatkan halaman website yang berisi bebsgai koleksi dari Rumah Baca Al-Sajarah, terutama koleksi buku dan foto dokumentasi. Jika dipilih salah satu buku, maka akan muncul judul, nama pengarang, penerbit, tahun dan tempat terbit serta ringkasan isi buku tersebut.

\section{KESIMPULAN}

Berdasarkan pada penelitian dan hasil uji coba lapangan, maka dapat disimpulkan bahwa tujuan penelitian ini sudah tercapai, yaitu merancang website Rumah Baca Alsyajarah sebagai media promosi untuk dapat meningkatkan minat untuk mengunjunginya. Uji coba lapangan dilakukan terhadap 30 orang yang terrdiri dari 5 orang dosen UIN Imam Bonjol Padang, 10 orang mahasiswa UIN Imam Bonjol Padang dan 10 orang mahasiswa Unirversitas Andalas Padang, 1 orang apresiator, dan 4 orang yang tinggal di sekitar rumah baca tersebut. Berdasarkan angket yang disebar dan diisi setelah dilakukan uji coba lapangan tersebut, dari 30 orang, 80\% menyatakan sangat setuju dan $10 \%$ menyatakan setuju bahwa website cukup menarik baik dari sisi tampilan maupun isi dan kemudahan penelusuran, sehingga user target ingin segera mengunjungi rumah baca tersebut.

Dilihat dari statistik pengunjung rumah baca yang diamati selama 3 bulan setelah promosi melalui website, terjadi peningkatan sekitar $25-50 \%$ pengunjung setiap minggunya. Dengan demikian penggunaan website ini sebagai media promosi cukup efektif, praktis, dan efisien.

\section{DAFTAR PUSTAKA}

Basba, Savynaz Endar. Promosi Perpustakaan Menggunakan Jejaring Sosial Facebook (Studi Deskriptif Mengenai Tanggapan Pengguna Terhadap Facebook sebagai Media Promosi Perpustakaan di Perpustakaan Universitas Airlangga), diakses pada 10 Oktober 2019.

Eriska,Veny dan Ramansyah. Pentingnya Rumah Baca. 12 Februari 2017. Diakses pada tanggal 12 Oktober $2017 \quad$ di http://www.medanbisnisdaily.com/m/news/read/2017/02/12/282971/pentingnya_rumah_baca/

Eryando,Tris. Handout Website sebagai Media Promosi Perpustkaan, diakses Tanggal 10 Oktober 2019.

Moprita,Tischa dan Desriyeni. Rancangan Media Promosi Perpustakaan di Perpustakan Universitas Negeri Padang. Diakses pada tanggal $10 \quad$ Oktober 2019 di file://C:/Users/USER\%20ID/Downloads/6182-12342-1-SM.pdf.

Priyogo, Sarastiti Dwi. Efektivitas Promosi Perpustakan dengan Menggunakan Sarana Media Internet, 2017. Diakses pada tanggal 10 Oktober 2019 di https://docplayer.info/47564330-Efektivitaspromosi-perpustakaan-dengan-menggunakan-sarana-media-internet.html

Sukarno,Giyan Luckty. Kegiatan Promosi Perpustakaan Melalui Media Sosial, 2016. Diakses pada tanggal 10 Oktober 2019 di http://perpus.sman2metro.sch.id/berita-kegiatan-promosiperpustakaan-melalui-media-sosial.html .

Sukirno. Optimalisasi Web untuk Promosi Perpustakaan. Jurnal Pustakaloka Volume 8 No 2, 2016. 